\title{
Multi-Agent Simulation for exploring export capable behaviors of Pakistani Small \& Medium Enterprises
}

\author{
${ }^{1}$ M.Irfan Azhar, ${ }^{2}$ Professor Rafi Javed Qureshi \\ ${ }^{I}$ Department of Mechatronics Engineering University of Engineering \& Technology, Taxila Chakwal, Pakistan \\ ${ }^{2}$ Department of Industrial Engineering University of Engineering \& Technology Taxila, Pakistan
}

\begin{abstract}
Pakistan's economy in the decades to come is an increase in country's manufacturing exports. The way global markets are evolving can work in favor of Pakistani SMEs and there is a huge opportunity that remains to be explored by Pakistan's business sector. An agent based model comprising of Pakistani SMEs; international markets; changing economic climate, SMEs capabilities and demands etc. was made. The results generated after the interactions of these agents show that for Pakistan, SMEs forming cooperative networks have better chances of growth and survival in the international markets. However, the assumption that different organizations cooperate for mutual benefits is subjected to some constraints like level of trust between these companies, risk of unwanted technology transfer and risk of key employees leaving the company for better opportunities provided by once so called network partners. In that case companies with more entrepreneurial traits will become successful. These companies can also survive in some of the most difficult scenarios, when market demand is low and competition is high. However, this form of entrepreneurship is not that common in Pakistan. Steps should be taken to promote innovative, creative and entrepreneurial qualities in SME owners and managers, so that Pakistani companies could explore more profitable hi-tech markets.
\end{abstract}

Keywords: - Agent Based Modeling; Small and Medium Enterprises; Internationalization

\section{Motivation}

Small and medium enterprises have a great significance when it comes to economy of a country. This is the sector where most of the jobs are created, creative ideas are generated and out of the box solutions are implemented. This benefits overall economy of a country since it is a highly volatile sector and many experiments are made by these organizations. Some of these workout pretty well and large scale manufacturing companies can also adopt these strategies for their betterment. Also, this sector has a good share in a country's manufacturing exports. Again, these exports have a great say in the economic balance of a country.

The interesting fact about these organizations is that they don't have stereotype cultures like most of the large scale manufacturing companies. Instead, these companies have their own ways. Since the employees are fewer and dominance of owner/owners is huge, this imparts unique qualities to these companies depending on the people who run these organizations.

For large scale enterprises, performance analysis is pretty straight forward, depending on their resources, cash and market demand etc. However, it is not that simple when it comes to SMEs. The unique attributes these companies possess can enable them to succeed in some very difficult scenarios and can sometimes be self destructing for them.

Agent Based Modeling and Simulation provides a platform that can be used to investigate how well or bad does an organization performs in a given situation and time span. This is ideal for highly volatile, dynamic and sometimes unexpected situations. The dynamics is important since a company could make one or two highly profitable deals and might seem to be very strong, but might fail in the long run. Similarly, a company might seem fragile, unsuccessful at that time and even untenable but might prove to be very successful as a result of how events unfold in the long run. The success or failure of an organization is dependent on internal as well as external factors. Internal factors include the qualities and internal structure of that company and external factors are those that are beyond the control of that organization.

\section{A BIT ABOUt ABMS (Agent BASED Modeling AND Simulation)}

ABMS is an exciting approach towards modeling complicated dynamic systems. An agent based model consists of intelligent decision making entities called agents. These entities are autonomous as they are capable of taking their own decisions and possess their own behaviors and attributes. These agents are the soul of the system and their performance is bounded by their own behaviors, strategies, goals, constraints, strengths and weaknesses. So, in such a model, there are multiple agents competing for similar and / or different or even conflicting goals. These autonomous entities can help other agents for achieving their objectives. These can also cause damage to other agents for their purpose. In a model, it is also possible to create entities / agents of different types. These agents may not be compatible with agents of other types. 
Another deciding factor in the model or a so called artificial world is the external environment. It is pretty much like natural calamities or luck that has the final say in determining a person / community's fate. These unusual or fate governing events for agents can also be modeled and made to behave in a time dependent manner. In Agent based modeling and simulation, it is considered another type of agent that has its own behaviors and constraints. The agents created in the model are made to interact with each other in the simulation part of ABMS. After these interactions, a situation arises as a result of competition, limitations and advantages over competitors and external factors. What we will be looking at will be the performance of contesting agents and the effect of that competition on the system itself. As the system is dynamic, any thing could happen; even some highly unexpected situations might arise! This will help in visualizing the scenarios that are favorable for some of the agents and inhibiting for others.

Here, an agent based model made for exploring export capable qualities and behaviors of Pakistani SMEs will be discussed. The model will also be useful in investigating external factors that can help or inhibit Pakistani SMEs in their bid to increase their role in international markets.

\section{KEY INPUTS FOR MODEL DEVELOPMENT}

For developing a model for companies competing for their survival in international markets, a lot of information and research is required. For developing an agent based model, we will be interested in behaviors of different entities that drive their fates. There are many factors behind these behaviors as well. However, we can take these behaviors for granted for simplifying things. For example, it will be a behavior for a firm to establish its outlets in different countries for earning more profit or for business expansion, after the firm has established itself at its home country. Similar behaviors are required for developing the model in which agents / entities pertaining to such business environments interact with each other.

The most useful information in that regard is provided by the theories of internationalization for business firms. These theories are helpful in modeling the behaviors that cause companies to grow in foreign markets. In the context of Pakistan's SME sector, if Pakistani SMEs internationalize, that would mean that the involvement of Pakistan will increase in international markets. That will be a sign of prosperity for Pakistan's economy.

There are three important theories that are considered for this model; the Uppsala model [4] proposed by Johansson and Wiedersheim-Paul (1975), Networking Theory [2] explained by Johanson and Mattson (1988) and the International Entrepreneurship Theory [7], a term coined by Morrow (1988).

The Uppsala model presents a gradual and cautious approach towards increased involvement in international markets. As explained by Johanson and Vahlne (1977), the internationalization of a firm in a particular market depends on the market knowledge of that firm about that market [3]. That knowledge leads to resource commitment which is a risk in foreign markets. That risk can pay off for firms if they manage their functions properly and successfully in international markets. However, it is a slow approach and the company following that strategy might find itself behind its rival firms if they follow quicker paths towards the internationalization.

One of these faster strategies towards internationalization is the networking approach. As hinted by to Mitgwe (2006), companies can attain rapid internationalization by sharing their resources and capabilities with other firms and partners that are a part of a network [6]. This idea is suitable to firms that specialize in their domains. This idea can also be beneficial for new companies that are looking for experience and channels for their access to international markets. This will help develop capabilities that will enable those firms to survive in foreign markets.

International Entrepreneurship theory (IET) is a new theory that has become popular over the years, considers an approach similar to the proverb "fortune favors the brave". McDougall and Oviatt (2000) consider international entrepreneurs to be extremely risky and opportunistic business venturers who could get huge success in very little time [5]. This theory has become popular as a result of advancements in IT and internet, current trends of e-business and ever decreasing trade barriers.

So, the behaviors of competing SMEs in the model will be governed by these internationalization theories. They will serve to provide appropriate strategies that will determine the performance of SMEs in international markets. Other important factors in determining SMEs fate in international competition are the capabilities of SMEs and external factors like demand, tax rates, inflation etc. For getting an insight to the business activities of exporting firms, a survey was conducted. Company owners were asked about important factors that could lead the companies to success in international markets. The survey provided useful information about key input parameters that are vital for a company's success in international markets. The results are based on the opinions taken from SME owners. The survey was very useful for understanding the SME internationalization process. It was a key input for developing the model since the importance of many factors was highlighted by the opinions of entrepreneurs. The results of the survey are presented in table I.

To feed information about the business climate in Pakistan, facts from Global Entrepreneurship Monitor (GEM) report were used [8]. As stated by Mian and Qureshi in GEM 2010 report for Pakistan (2011), 27.73 \% 
participants in the survey stated that fear of failure is the main cause that stops from starting a business [8]. This percentage is low if compared with similar developing countries. Growth aspirations were modest amongst the entrepreneurs if compared with other developing countries. This information was used in the model for assigning different goals and strategies to Pakistani SMEs. This is also important in deciding when an SME opts to quit its business activity. If growth aspirations are not that high, the entrepreneur might decide to do something else. This is one of the key behaviors that need to be modeled in such agent based models. There are other factors that can also be used to model SME failures, like if the SMEs fail to pay their debts and default. Similarly, if the wealth of an SME increases to certain level, it might decide to take the next big step or grow. In terms of the model at hand, it means that the company will internationalize. The mode of internationalization depends on the nature and resources owned by the owner of that SME. Some entrepreneurs will be cautious while others might take more risks for early internationalization.

TABLE I. ENTREPRENEUR'S OPINION ABOUT IMPORTANT BUSINESS FACTORS

\begin{tabular}{|c|c|c|c|c|}
\hline $\begin{array}{l}\text { No } \\
\text {. }\end{array}$ & $\begin{array}{l}\text { Some Important } \\
\text { Parameters }\end{array}$ & $\begin{array}{l}\text { Mea } \\
\mathrm{n}\end{array}$ & $\begin{array}{l}\text { Standa } \\
\text { rd } \\
\text { Deviati } \\
\text { on }\end{array}$ & Score \\
\hline 1 & $\begin{array}{l}\text { Entrepreneur's } \\
\text { Nature }\end{array}$ & 1.05 & 0.221 & $\begin{array}{l}38 \quad / 40 \quad \text { were } \\
\text { expansion } \\
\text { believers }\end{array}$ \\
\hline 2 & $\begin{array}{l}\text { Entrepreneur's } \\
\text { entry mode to } \\
\text { internationalizat } \\
\text { ion }\end{array}$ & - & - & $\begin{array}{lcc}27 & / & 28 \\
\text { incremental } & \end{array}$ \\
\hline 3 & $\begin{array}{l}\text { International } \\
\text { Relations. }\end{array}$ & 4.21 & 2.63 & $\begin{array}{l}21 / 38 \text { believed I.R } \\
\text { are important. }\end{array}$ \\
\hline 4 & Product Price & 4.53 & 2.47 & $\begin{array}{l}25 / 40 \text { believed it } \\
\text { is important }\end{array}$ \\
\hline 5 & Product Quality & 5.43 & 2.561 & $\begin{array}{l}32 / 40 \text { believed it } \\
\text { is important }\end{array}$ \\
\hline 6 & $\begin{array}{l}\text { International } \\
\text { Certification }\end{array}$ & 4.8 & 2.747 & $\begin{array}{l}28 / 36 \text { believed it } \\
\text { is important. }\end{array}$ \\
\hline 7 & $\begin{array}{l}\text { Responsive } \\
\text { speed }\end{array}$ & 4.57 & 2.591 & $\begin{array}{l}25 \text { / } 38 \text { believed it } \\
\text { is important }\end{array}$ \\
\hline 8 & Taxes & 3.3 & 3.006 & $\begin{array}{l}20 \text { believed it is } \\
\text { important. }\end{array}$ \\
\hline 9 & $\begin{array}{l}\text { Role of } \\
\text { Universities and } \\
\text { technical } \\
\text { Education }\end{array}$ & 3.3 & 2.91 & $\begin{array}{l}18 \text { / } 27 \text { believed } \\
\text { universities have a } \\
\text { role. }\end{array}$ \\
\hline 10 & $\begin{array}{l}\text { Transportation } \\
\text { and Logistics }\end{array}$ & 3.31 & 2.783 & $\begin{array}{l}16 / 27 \text { believed it } \\
\text { has a significance }\end{array}$ \\
\hline
\end{tabular}

Finally, we need to know where the SMEs of that country stand in the international competitive markets or whether the SMEs of that country can meet the demands of the markets of a certain region or not. All these factors when combined can be very useful in the model development for the research question presented in this paper.

\section{Agent BASED MODEL FOR THE SYSTEM}

The next step is the development of the agent based model for the problem. NetLogo was used for the model development.

The model consists of different entities or agents with their goals or objective functions, time variant external environment affecting the performance of these agents, behaviors of agents that enable them to react to certain scenarios and finally, the interactions between these agents.

The model description could be a very lengthy and complex task depending on the models. However, the ODD protocol [1] formulated by Grimm and Railsback (2005) provides a valuable way of presenting these models in a comprehendible manner. That same protocol can be used to describe the model developed for the 
SMEs in this paper. Tables II, III and IV provide the model description for the model for SMEs and the questions in focus for this model using the ODD protocol.

\section{A. Overview}

Table 2 presents an overview of the model. Model purpose,

various agents or entities and process overview are described in that table. It provides a brief outline for the functioning of the model. So, we have SMEs that are trying to sell their products to international markets. If these SMEs fulfill the demands of international customers, they get orders from those customers. This increases their wealth and improves their reputation. After attaining a certain level of success, the companies try to maximize their wealth and influence by internationalization. This could lead to growth and success as well as failure and exit from the market. That is what we will be investigating, the qualities that enable the companies to survive for a long time and increase their involvement in foreign markets.

TABLE II. OVERVIEW OF THE MODEL

\begin{tabular}{|l|l|}
\hline Overview & $\begin{array}{l}\text { Purpose: A model for exploring qualities of } \\
\text { SMEs and scenarios that will enable the } \\
\text { Pakistani SMEs to survive and grow in the } \\
\text { international markets. }\end{array}$ \\
Entities: The model consists of Pakistani \\
SMEs, International markets/distributers, Skill \\
agents, raw material agents, communication \\
agents, creativity agents, technology agents, \\
international competitors of Pakistani SMEs \\
and the environment. \\
Process Overview \& Scheduling: \\
International Markets have rapidly changing \\
demands like skill, cost, quality, creativity etc. \\
Pakistani SMEs have certain capabilities \\
depending on the team of agents working for \\
that SME. If a Pakistani SME meets the \\
demands of an international market, it gets a \\
purchase order from that market. The wealth of \\
that SME increases and it aims for growth or \\
internationalization. This could lead to success \\
or failure of the SME as internationalization \\
has a cost and if the SME fails to find enough \\
customers in the international markets, it will \\
not be able to survive.
\end{tabular}

\section{B. Design Concepts}

After presenting the overview, we need to think how we should design the model to get the desired results. We are creating an artificial world which works exactly in the same way as importers and exporters interact. To make things happen the way we want, we have to put some constraints on the system. The effect will be to cause agents to act in certain ways governed by rules fed to the model.

In the model, we have entities behaving in a way very similar to real life business organizations. These entities sense opportunities that can make them successful. These entities also adapt to changing scenarios. For example, when they are not getting any orders, they need to make changes in their strategies. They could select more skillful employees to boost their business. Another adaptive behavior is the improvement in the strategy of SMEs forming cooperative networks with other SMEs. These SMEs gradually increase their demands for creativity, technology and skill as they acquire experience from their network partners. Similarly, an SME owner might have a risky nature but could follow a more conservative path

towards growth if business climate is not that encouraging for ambitious ventures. Wealth can be used as a parameter that controls the path towards growth for an SME.

These adaptations are made in accordance with the objectives set for these SMEs. Some SMEs have a goal to grow their business in very quick time. Some might prefer security over ambitious growth plans. 
The above mentioned concepts are not limited to SMEs only. Rather, they apply to all agents. International markets also sense and search for SMEs meeting their demands. There objective is to find the SME meeting their demand and providing the product at a reasonable cost. Also, these markets change their ways with changing competition between SMEs struggling for market control in those regions.

How different agents in the model interact with each other is another important concept that has an impact on the model. For example, how does creativity agent or other agents like skill, technology etc. influence the performance of an SME? In the model, an SME cannot get orders if does not have a complete team of agents working for it. Also, business interactions are modeled which increase the wealth of an SME when it receives an order from an international firm.

Another important aspect of the model is the use of random numbers for different agent attributes. All agents have some qualities that are assigned some random numbers. This creates a wide difference between the performance and behaviors of these agents. For example, in the model, every SME is assigned a random number for one of its attributes named "perception". Perception is a variable that represents the lower limit of the amount of wealth possessed by an SME after which the SME will opt for loan to continue its business activities. Similarly, all SMEs are assigned random numbers for their creativity, skill, quality and material demands. Skill, creativity, technology and raw material agents etc. also have random numbers set for their skills. If an agent possesses a skill level greater than the demands of an SME and is within a certain distance from that SME, it will be hired by that SME. International market demands are also represented by random numbers. These demands are also reset after every 60 ticks in the model. This interval corresponds to a time duration of 15 days.

Now all the agents behave in a way governed by these design concepts. The model world is dynamic where situation is always changing. This change has an influence on the agents as well. Now, we will be interested to know how the overall system is behaving. For our purpose, this will be outcome of the model showing the type of SMEs that has better chances of success as compared to other SMEs. We will also know about various scenarios that cause a certain type of companies to become more successful as compared to other type of SMEs. Table III presents the design concepts according to ODD protocol.

\section{TABLE III. Dessign CONCEPTS OF THE MODEL}

\begin{tabular}{|c|c|c|}
\hline $\mathrm{D}$ & $\begin{array}{l}\text { Design } \\
\text { Concept } \\
\text { s }\end{array}$ & 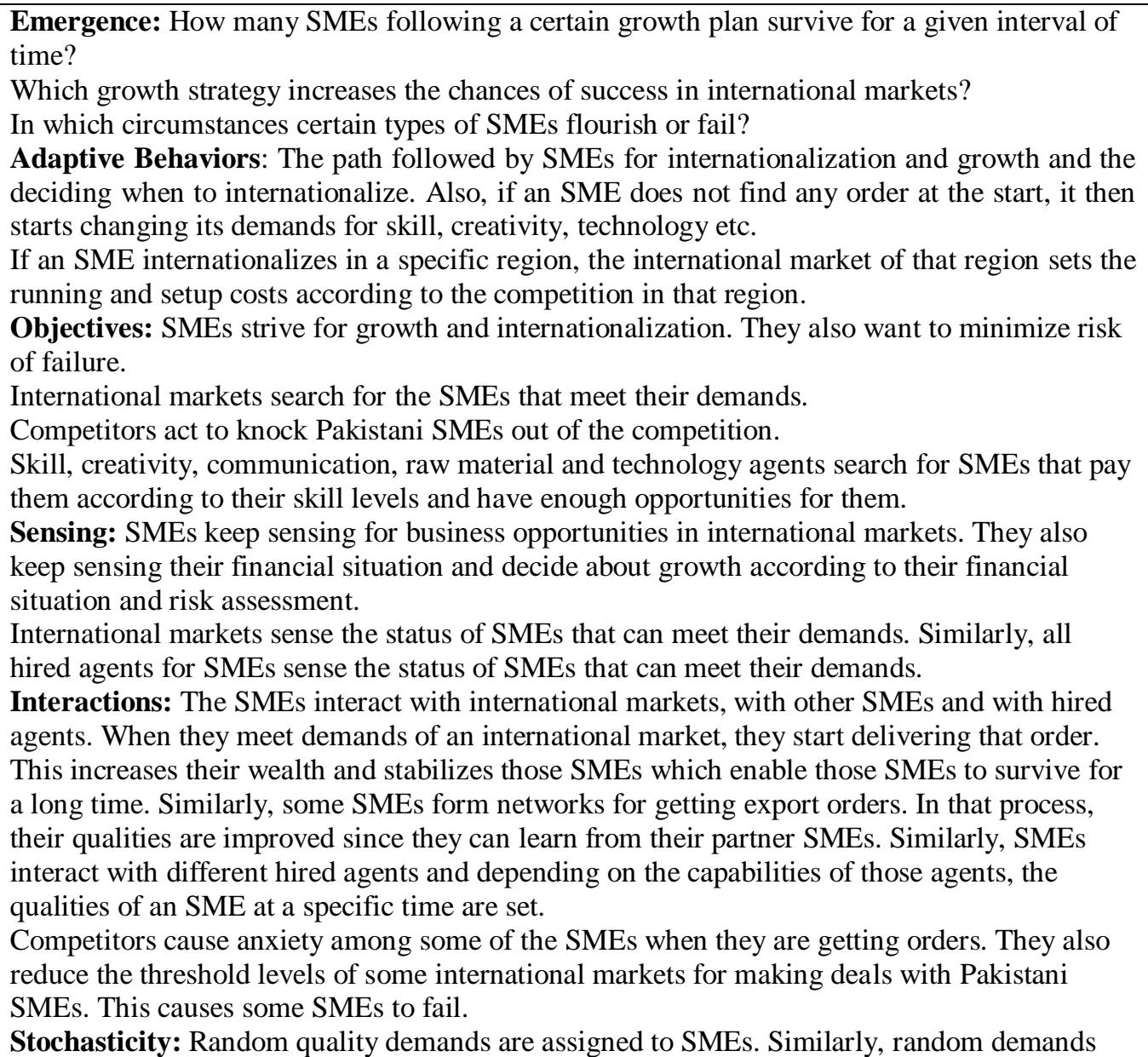 \\
\hline
\end{tabular}




\begin{tabular}{|l|l|}
\hline & $\begin{array}{l}\text { and qualities are assigned to international markets and agents like technology, communication, } \\
\text { raw material, skill, creativity etc. } \\
\text { Also, risk assessment is random for all SMEs. }\end{array}$ \\
\hline
\end{tabular}

\section{Details}

After making the model for the system, we will be interested in knowing how the system responds to various situations. Knowing the system, we will conduct various experiments on the model to get information of our interest about that particular model. This is where results for the problem statement will be coming.

We need to specify how the model conditions were set up at the start, how various parameters vary as time progresses and how to investigate the effect of various factors on the system. For the model developed for this problem, we need to specify initial values of demands, wealth and quality levels of international markets, SMEs and other team agents for SMEs. These values will change as time progresses. The values will depend on interactions between agents. After that, we will try different things using the same model but different values $\mathrm{f}$ or key parameters. For example, one interest will be to investigate the effect of law and order situation on the system. The other will be to see the effect of international demand variations on the performance of SMEs. Table IV presents the details protocol concepts for the model.

TABLE IV. DETAILS FOR THE MODEL

\begin{tabular}{|l|l|l|}
\hline D & Details & $\begin{array}{l}\text { Initialization: Initially, the number of SMEs, international markets, skill, creativity, } \\
\text { communication, technology agents etc. is set to 10. All SMEs have 1000 units of wealth } \\
\text { initially. There are patches in the model that are rich in material resources. There is } \\
\text { randomness in that resource richness. Similarly, all agents are assigned capabilities that are } \\
\text { random initially. } \\
\text { Input Data: Data from the survey conducted was used for that purpose. Similarly, logics from } \\
\text { internationalization theories and GEM were fed to the model. } \\
\text { Sub models: Various experiments were performed on the model by introducing certain } \\
\text { variations. Demands in the international markets, law and order situation in Pakistan, taxes } \\
\text { and interest rates, SME characteristics etc. were changed to see the effect of those variations } \\
\text { on the system. }\end{array}$ \\
\hline
\end{tabular}

\section{KEY CONCEPTS AND AGENT INTERACTIONS IN THE MODEL}

The previous section presented an overview for the model. Here, key interactions between agents will be described. This will help in understanding the model further.

\section{A. Time and agent movements}

The model runs for 50000 clock ticks. This number of ticks is sufficient to investigate the model for parameters of interest. SMEs and international markets remain stationary during that time but all team agents like skill, creativity, technology agents etc. keep moving during the simulation. These agents stop when they are hired by an SME. This happens when these agents meet the demands of an SME. These agent movements are important since it allows agents to search appropriate boss SMEs for themselves and SMEs also depend on these agents for their operations. Raw material agents are stationary when there is no demand for them. They have their material quality set to the quality of material of the patch or place where they are standing. When an SME receives an order from international markets, it generates a demand signal for these agents and they start moving towards that SME to provide raw material to that agent.

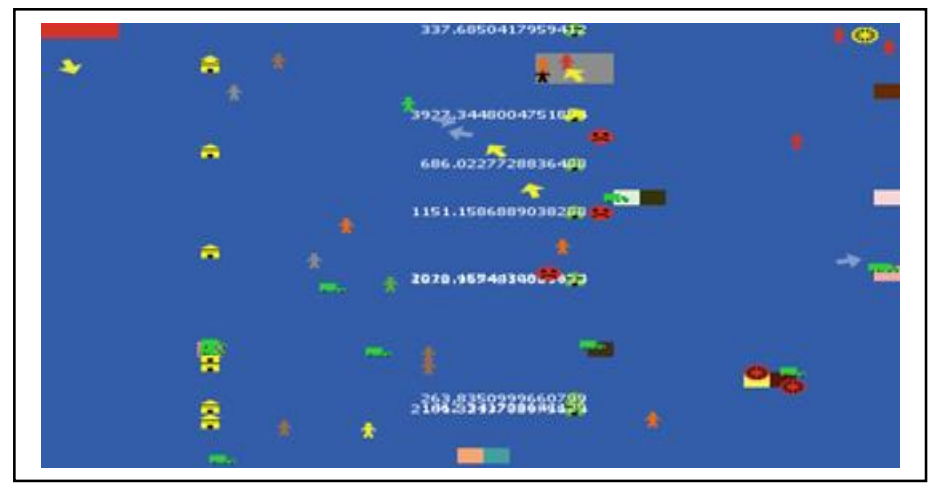

Figure 1. SME hiring skill and creativity agents shown in grey patches while raw material agents (green trucks) stay at resource rich patches with colors other than blue. 


\section{B. Setting Agent demands, qualities and external factors}

Demands for international markets are reset after every 60 ticks. Demands for SMEs remain the same if they get export orders. If SMEs are a part of a cooperative network, their production capacity and demands for creativity, skill and technology increase incrementally to the demands and capacity of the SME with the highest value of these attributes, depending on their learning rate and wealth. Skills of team agents serving SMEs are reset after every 80 ticks. This enables hired agents to become disengaged from the control of SMEs if their skills do not match the skills required by SMEs.

Patch behaviors can be set to model external factors. Every patch has resistance to motion of raw material agents and potential for law and order turmoil. Patches that are not blue are supposed to be rich in material resources. Similarly, there are various sliders used to control government taxation policy, interest rate, demand in international markets and effect of competitors from other countries on SMEs etc.

\section{SMEs and international market interactions.}

International markets have certain demands pertaining to quality, creativity, skill and quantity. If an SME meets those criteria, then it gets an order from that market. If an SME has worked for a customer, it will get preference for the next order. Similarly, there are some SMEs that seek opportunities in foreign markets in a more proactive manner. These SMEs are modeled on international entrepreneurship theory. These SMEs seek opportunities via their communication agents that have sensing capabilities in certain distances. SMEs modeled on networking theory have their socializing attributes higher than other SMES. If they find similar SMEs within close vicinity, they form networks. This makes it easy for these SMEs to get export orders since they use the best combination of qualities necessary to get orders.

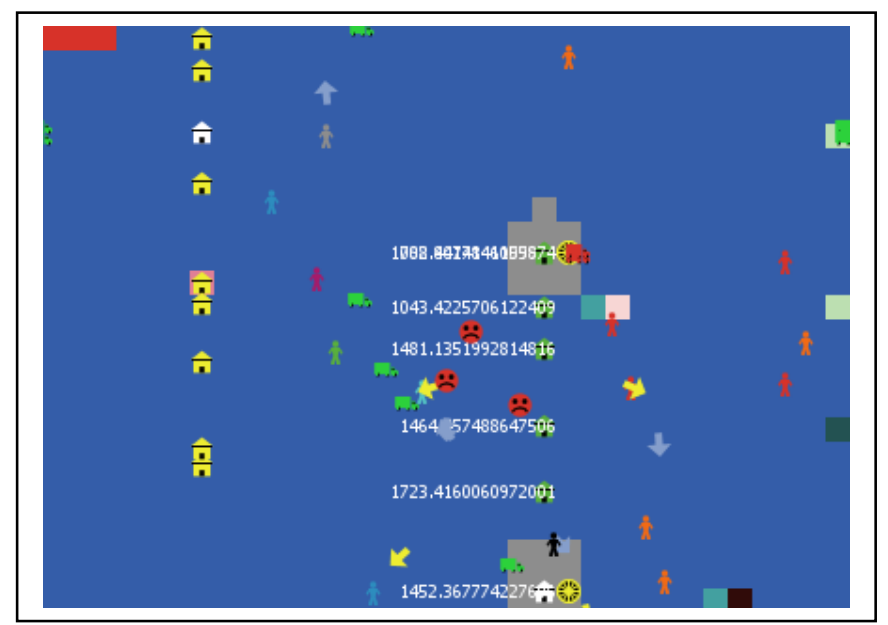

Figure 2. International markets (yellow) with opportunities for SMEs with pink patches in their vicinity while communication agents sense these opportunities. White market busy in a deal with an SME (white).

When an SME or a network of SMEs gets an order, they start delivering that order to the customer. There is a time given to these SMEs in which they have to complete the order. They complete the order incrementally depending on their production capacity and material availability. As they deliver a certain number of items to the customer, their wealth increases depending on the cost of that product. After the order is completed, the rating of the SME increases in that market. This represents experience of that SME in that market.

\section{SME growth and Failure}

This is where the internationalization theories come into play. There are four types of SMEs operating in the model. The first type of SMEs follows an incremental approach towards internationalization i.e. the Uppsala model. These companies try to acquire sufficient knowledge and experience about international markets before they increase their role in those markets by establishing distribution centers or production facilities. The second type of SMEs search opportunities in international markets and multiply their wealth very quickly. These SMEs follow the international entrepreneurship theory model. SMEs of third type are the SMEs that that form networks to get export orders. These SMEs rely on their relations with their network partners for their success. Finally, the fourth type of SMEs is entrepreneurial as well as well as social i.e. forms networks with other SMES. Every SME has a perceived value of wealth and experience that is necessary for the growth of that SME. So, when an SME has sufficient wealth and has completed a certain number of orders in an 
international market, then it can internationalize at that region. These values are different for different SMEs depending on their nature. SMEs of type one is more conservative and minimizes risk before these SMEs enter international markets. Entrepreneurial SMEs internationalize early. Figure 3 presents the logic for that decision.

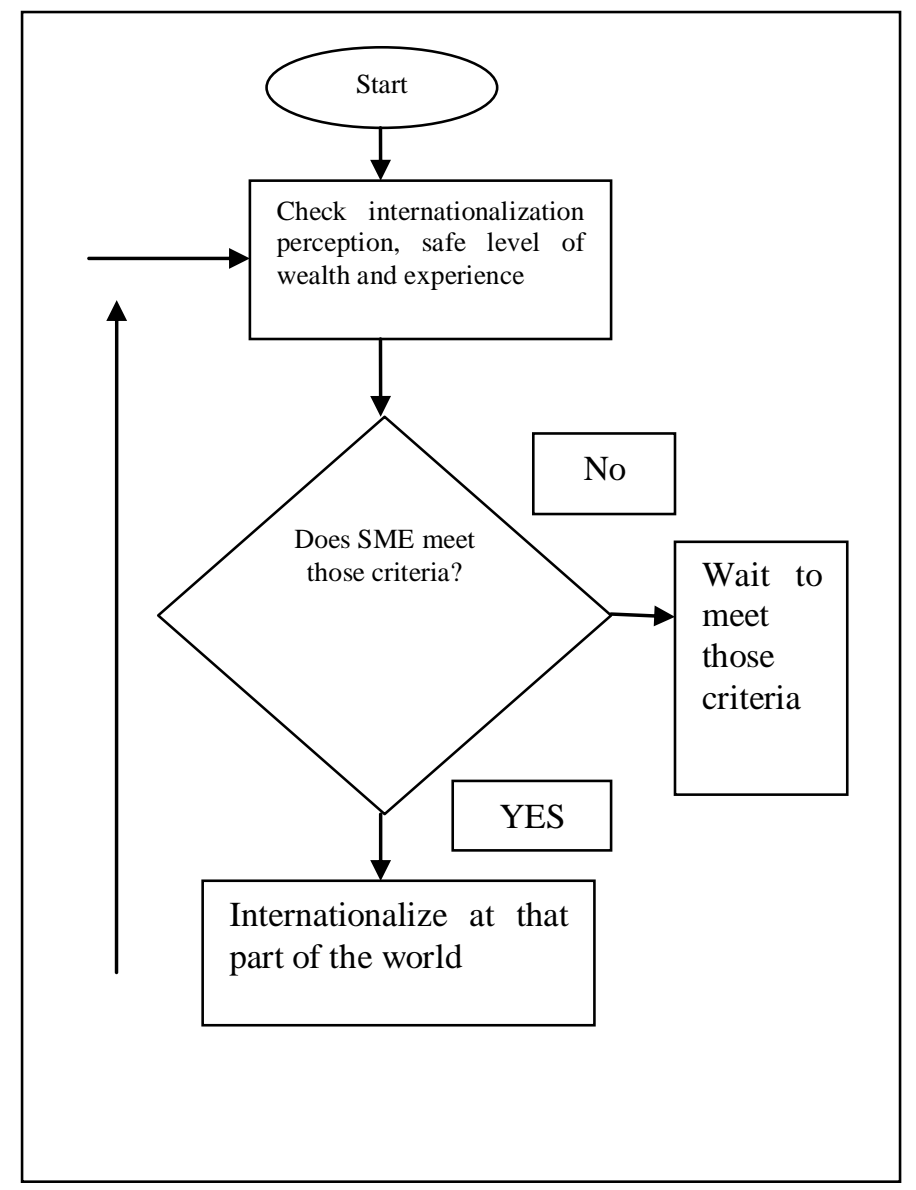

Figure 3. Logic diagram for SMEs internationalization process

The SMEs can earn huge amounts of wealth if they are successful in international markets. However, there is also a risk for their failure as these markets have their own dangers and competition. In addition, these markets are expensive for these SMEs and have high setup and running costs for business. These things can cause SMEs to fail if their wealth does not increase and loans keep mounting to a level where the company defaults.

Another thing can cause an SME to exit from business is entrepreneur's choice. If a company is not getting enough orders, the entrepreneur might lose his patience with that business and might opt to exit. For that, every SME has an attribute called temperament which reduces with every tick when and SME does not get any orders. When an SME gets an order, this value is set to a high positive number like 1000. Competitors can also cause SMEs to lose their interest in business. They cause international customers to reduce their preference for Pakistani SMEs when they get more orders. This will cause anxiety and uncertainty among the SMEs and they will opt to exit when they lose their patience.

Similarly, every SME has its running cost. When it does not get orders, its financial condition become worse and it opts for loans. If these loans become greater than the assets of that SME, it defaults.

\section{EXPERIMENTS AND RESULTS}

The model was tested for various scenarios. These include

- Which SMEs are successful when level of trust between SMES is not high for forming cooperative networks?

- Which SMEs have a better chance of success when international demands vary from very high to very low

- Effect of quality demands in international markets on SMEs 
- What is the effect of interest rate on SMEs

- How are SMEs influenced by law and order situation

- How are SMEs influenced by competitors

- Effect of transportation on SMEs performance

The results obtained after simulation suggest that SMEs forming cooperative networks have better chances of success considering Pakistan's scenario. This is because there are companies that have attained sufficient knowledge and experience about international markets. However, resource shortage can be a problem when it comes to materials and expertise in certain areas. If these companies collaborate with relatively young companies, aspiring for internationalization, this could benefit both types of firms.

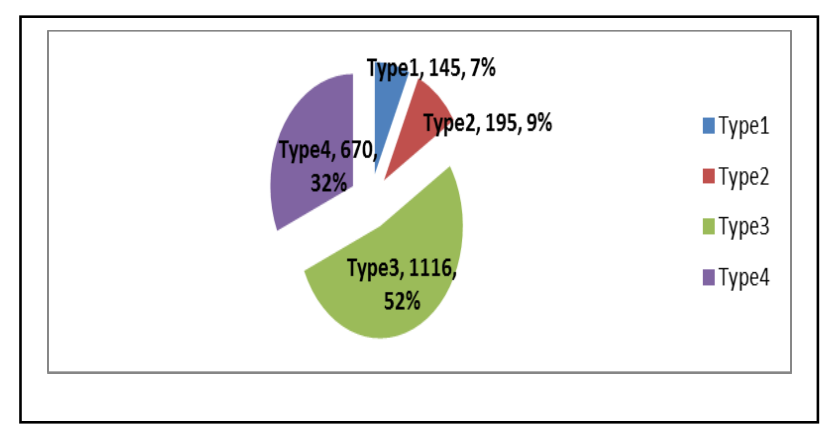

Figure 4. Results after 50 simulations for SMEs by type surviving for longer periods of time. SMEs of type 3 and 4 dominate.

However, there are certain risks associated with networking strategy as companies might lose their control in order to comply with requirements set by other network partners. There is also a risk of technology transfer and companies might not like to share their success secrets with other firms. In that case, companies with more entrepreneurial attributes will dominate. Table V presents the results when SMEs don't trust other SMEs for forming networks.

Table V. Number of type of SMEs surviving for 2000, 4000 and 8000 ticks

\begin{tabular}{|l|c|c|c|c|}
\hline Type of SME & Less than 1000 ticks & 2000 Ticks & 4000 Ticks & 8000 Ticks \\
\hline Incremental & 275 & 0 & 0 & 0 \\
\hline Entrepreneurial & 8 & 7 & 6 & 2 \\
\hline Networking Strategy/Social & 6 & 0 & 0 & 0 \\
\hline Entrepreneurial + Social & 2 & 1 & 0 & 0 \\
\hline
\end{tabular}

The summarized results of other experiments are presented in the table below.

TABle VI. Summarized Results

\begin{tabular}{|l|l|}
\hline Parmeter & Effect \\
\hline $\begin{array}{l}\text { Quantity } \\
\text { Demand }\end{array}$ & $\begin{array}{l}\text { When Demand is low, entrepreneurial SMEs have better chances of success. } \\
\text { Networking SMEs have better chances of success when demand is high. } \\
\text { More SMEs fail when demand is low. }\end{array}$ \\
\hline $\begin{array}{l}\text { Quality } \\
\text { Demand }\end{array}$ & $\begin{array}{l}\text { Entrepreneurial SMEs perform best when quality demands are high. } \\
\text { Networking SMES also have better chances of success when quality demands are high. }\end{array}$ \\
\hline Interest Rate & $\begin{array}{l}\text { More SMEs fail as interest rate is increased. } \\
\text { Entrepreneurial SMEs don't depend much on interest rates. } \\
\text { Networking SMEs can survive at high interest rates }\end{array}$ \\
\hline $\begin{array}{l}\text { Law } \\
\text { Order }\end{array}$ & Networking SMEs have the best chances for success when law and order situation is adverse. \\
\hline Competitors & $\begin{array}{l}\text { Time spent by companies in international markets drop dramatically as competition increases. } \\
\text { Networking SMEs perform best when competition is high followed by the entrepreneurial } \\
\text { SMEs. }\end{array}$ \\
\hline $\begin{array}{l}\text { Transportati } \\
\text { on }\end{array}$ & $\begin{array}{l}\text { Networking SMEs and entrepreneurial and collaborating SMEs can perform well if } \\
\text { transportation is slow and prone to delays. }\end{array}$ \\
\hline
\end{tabular}


Also, a pattern was observed for networking SMEs while running the simulations. The companies forming networks survived for longer times. After that, these companies had a tendency to fail in groups, one company following the other in exit from business. Then there were times when no companies survived for longer times and then the cycle repeated itself. This is a consequence of companies not adapting to changing demands of international markets. These companies enjoy success for some time but fail to respond to changing demands of international market and fail eventually. Since companies start to exit, the overall network becomes weaker and eventually most of the companies fail. Since it is a dominant behavior for successful companies, the cycle repeats itself again and again with new companies forming networks and surviving for longer durations of time. Table VII shows the number of SMEs of type 3 at different times during one of the simulation runs.

TABLE VII. NUMBER OF SMES OF TYPE 3 SURVIVING AT A GIVEN INSTANT

\begin{tabular}{|l|l|l|}
\hline Sr. no & Time & SMEs with life > 1000 ticks and type 3 \\
\hline 1 & 1000 & 1 \\
\hline 2 & 1800 & 4 \\
\hline 3 & 2100 & 3 \\
\hline 4 & 3100 & 1 \\
\hline 5 & 6000 & 3 \\
\hline 6 & 7000 & 4 \\
\hline 7 & 7800 & 4 \\
\hline 8 & 8000 & 5 \\
\hline 9 & 8600 & 6 \\
\hline 10 & 9000 & 5 \\
\hline 11 & 9600 & 4 \\
\hline 12 & 13400 & 5 \\
\hline 13 & 14000 & 3 \\
\hline
\end{tabular}

\section{CONCLUSION}

Agent based modeling can generate interesting results for such problems. For the problem presented here, it can be concluded that many factors dictate the fate of Pakistani SMEs. Pakistan having a factor driven economy, as stated by GEM (2011), does not have a developed infrastructure for entrepreneurship. This result in too few entrepreneurial and born global Pakistani SME sector is concerned. However, if awareness is increased about entrepreneurship and entrepreneurial behaviors via education and promotion, Pakistani SMEs might capture some high valued markets as well. Such firms can survive in tense economic climates where most other firms fail. These firms can perform well under intense competition from other markets and during phases of recession. Networking SMEs also work well under similar circumstances but rely on high demand in international markets. Such networks will also help in reviving Pakistan's industrial sector as firms will take advantage of their partner's best qualities and practices.

\section{REFERENCES}

[1] Grimm and Railsback. Agent-Based and Individual Based Modeling - A Practical Introduction, 2005 Chap. 10 Princeton University Press, Princeton, NJ.

[2] Johanson, J., \& Mattsson, L.G., 1988. "Internationalization in industrial systems: A network approach",In: Hood, N., Vahlne, J-E., (eds), Strategies in global competition. Croom Helm, London, pp. 194-213.

[3] Johansson, J., \& Vahlne, J-E., 1977. "The Internationalization Process of the Firm-A Model of Knowledge Development and Increasing Foreign Market Commitments", Journal of International Business Studies, Vol. 8, No.1, pp .23-32.

[4] Johansson, J., \& Wiederscheim-Paul, F., 1975. "The internationalization of the firm - four Swedish cases", Journal of Management Studies, Vol. 12, No. 3, pp. 305-322.

[5] McDougall, P.P., \& Oviatt, B.M., 2000. "International entrepreneurship: The intersection of two research paths" Academy of Management Journal, Vol. 43, pp. 902-908.

[6] Mitgwe, B., 2006. "Theoretical Milestones in International Business: The Journey to International Entrepreneurship Theory", Journal of International Entrepreneurship, Vol. 4, pp. 5-25.

[7] Morrow, J.F., 1988. "International entrepreneurship: A new growth opportunity", New Management, Vol. 3, pp. 59-61.

[8] Sarfraz A. Mian and M. Shahid Qureshi "Pakistan Report 2010". Global Entrepreneurship Monitor (GEM) report for Pakistan, 2011, pp 05. 